http://jmscr.igmpublication.org/home/ ISSN (e)-2347-176x ISSN (p) 2455-0450

crossref DOI: https://dx.doi.org/10.18535/jmscr/v9i3.24

\author{
Journal Of Medical Science And Clinical Research \\ IGM Publication \\ An Official Publication of IGM Publication
}

\title{
Risk Factors for Abruptio Placentae - A Case Control Study
}

\author{
Authors \\ Dr Shyja JS ${ }^{1}$, Dr Fouzia $B^{2}$, Dr Nirmala $C^{3}$ \\ ${ }^{1}$ Post graduate student, Dept of Obstetrics and Gynaecology, SATH, Govt. Medical College, \\ Thiruvananthapuram \\ ${ }^{2}$ Assistant Professor in Dept. of Obstetrics and Gynaecology, SATH, Govt.Medical College, \\ Thiruvananthapuram \\ ${ }^{3}$ Retd. Professor in Dept. of Obstetrics and Gynaecology, SATH, Govt. Medical College, \\ Thiruvananthapuram
}

\begin{abstract}
Abruption is a serious complication of pregnancy and a leading cause of maternal and perinatal mortality \& morbidity. The objective of the study was to identify risk factors for placental abruption that may be amenable to interventions which can results in impaired feto maternal outcome.

Materials and Methods: This was a case control study conducted in SAT Hospital, Thiruvananthapuram. A total of 77 cases of abruption and controls were investigated. Statistical analysis for comparing low risk factors were done using Chi square test, Student's test and ' $p$ ' value, Odd's Ratio $(O R)$ and confidence intervals were also calculated.

Results: There were 77 cases of abruption during the study period. Advanced maternal age (OR - 5.87, CI - 0.135-0.618), multiparty (OR - 4.6 CI - 1.2-18.1) were significantly associated with abruption. Increased incidence of abruption was found among low socioeconomic status and referred cases. PIH was a major risk factor associated with abruption (27.3\% vs $9 \%$ in controls). $P<0.01$

Conclusions: The results indicate that placental abruption is an obstetric emergency with maternal and perinatal mortality. Advanced maternal age, multiparity, low socioeconomic status were the major sociodemographic factors associated with abruption. Previous caesarian delivery and PIH were the obstetric risk factors for abruption.

Keywords: Risk factors, abruptio placentae, feto maternal outcome.
\end{abstract}

\section{Introduction}

Abruption is a serious complication of pregnancy and a leading cause of maternal and perinatal morbidity and mortality. The rate of placental abruption has ranged in various studies from 3 to 16 per thousand. This wide range probably reflects the disparity in socio-economic groups and the difference in criteria employed for the diagnosis. Ours being a referral hospital the incidence is not very low.
On one hand the complexity in aetiology, diagnosis and management in abruption has contributed to the high incidence of maternal and perinatal mortality. The main causes of maternal mortality being hypovolemia and coagulatory failure and perinatal mortality due to prematurity and hypoxia. On the other hand the improvements in early diagnosis and immediate start of treatment and attempts to empty the uterus with in 8 -10hrs of start of abruption have decreased 
complication and thereby decreased the mortality and morbidity. But unfortunately inspite of the awareness among patient and medical staff such patient are brought to the major hospitals after hours of bleeding which leads to poor prognosis. On the whole a gradual and significant decrease in maternal mortality has been noted but the perinatal mortality is still high.

\section{Relevance of the study}

Because abruption is associated with high risk of adverse perinatal and maternal outcome and the incidence of abruption was $0.4 \%$ in 2003 and $0.6 \%$ in 2004 which shows an increase in the incidence in SAT Hospital even though the parity isdecreasing, this study proposes to identify risk factors associated with abruption that may be amenable to intervention which may help in decisions about obstetric treatment in cases of abruption to improve its outcome.

\section{Guidelines for routine management of abruption in SAT hospital}

There was a general plan of approach of all cases of antepartum haemorrhage admitted in SAT Hospital. A detailed history of the patient was quickly taken after admission. It included - Name, age, address, occupation, educational status, monthly income, obstetric score (no. of gravida, parity, abortion, still births / IUDs); Mode of delivery in previous pregnancies; Medical history included history of thrombotic episodes, chronic hypertension, Overt diabetes, Bronchial asthma, cardiac disease etc. Family history thrombotic episodes, history of trauma and additions like smoking, alcoholism and cocaine abuse is noted. The period of amenorrhoea and history of bleeding, trauma and obstetric illness in the present pregnancy are also noted. General examination is done to assess pallor, tachycardia or hypotension. Obstetric examination is done to look for the height of the fundus, consistency of the uterus - tense or tender. The presentation, lie and position of the fetus is assessed and fetal hearts sounds are auscultated, if present rate and rhythm is noted.
After quick history taking and clinical examination, intravenous access is made with the help of a 16-18 gauge IV canula to administer fluids and blood, when needed. 10cc venous blood is drawn for investigations. Estimation of haemoglobin, packed cell volume, bleeding time, clotting time, blood grouping and $\mathrm{Rh}$ typing, platelet count, liver function and renal function profiles are done.

A sample of blood is cross matched to get compatible blood for transfusion and a sample is used for doing clot observation test. The patient is catheterized to asses volume and color of urine. Urine is examined for albumin sugar and deposits. A foley's catheter is left in situ and a careful record of intake and output is maintained

USG is done to rule out placenta previa, to look for retroplacental clot and to confirm fetal heart activity and lie and presentation of the fetus.

After making a diagnosis of abruption, vaginal examination is done. Labour is accelerated by artificial rupture of membranes in all suitable cases. After ARM, oxytocin drip is started to accelerate labour in case of inadequate contractions. Abdominal delivery is resorted to in cases of obstetrical indications and complications and when the case did not respond to routine line of management.

\section{Why the study is under taken}

The incidence of abruption has been increasing in SAT Hospital, Trivandrum. The incidence of abruption in 2003 was $4 \%$ and $0.6 \%$ in 2004.Inspite of our decreasing parity and improved antenatal care, abruption remains a major contributing factor for increased perinatal morbidity and mortality. Even though maternal mortality due to abruption and disseminated intravascular coagulation has come down due to active intervention and timely use of blood and blood products, still it remains a matter of concern and hence this study was undertaken to find out the risk factors associated with abruptio placentae. 


\section{Materials and Methods}

This study is done to analyse the various risk factors associated with abruption among women aged 18-40 years old and between gestational age 28-40 wks., who attended SAT hospital, Thiruvananthapuram.

The aim of the study is to assess the risk factors associated with abruptio placentae.

Study Design: This is a case control study.

\section{Study Setting}

This study was conducted in SAT hospital, Thiruvananthapuram, Kerala, which is a tertiary referral centre and teaching hospital. This hospital caters to Trivandrum district and to neighboring districts in case of problem care management.

\section{Study Duration}

The study duration was from 1 year period

\section{Sample size}

It was decided to include all cases of abruption in the study during the one year period. A total of 77 cases of abruption and equal number of controls were studied.

\section{Study Population}

The study population included cases and controls. Cases were defined as those admitted with clinical signs and symptoms of abruption between gestational age 28-40 wks. Those which developed features of abruption while in hospital and those where abruption was diagnosed only after delivery, during the study period were also included. Referred cases were also studied. Same number of controls were taken in a random fashion from the obstetric register which is maintained in SAT Hospital, Thiruvananthapuram. Controls were defined as women between age group 18-40 years at 28-40 weeks gestation without signs and symptoms of abruption.

\section{Variables studied were}

Taken from patient's previous record whenever available or from patient's history.

1. Demographic variables identified were age in years, period of gestation, subjects with previous abortion and parity. Parity was identified as primipara and multipara. A primipara is defined as a woman who is delivering for the first time (after 28 wks of gestation). Primipara includes woman with history of abortions. Multipara is defined as a woman who has previously delivered a baby.

\section{Booking status}

Booked cases in SAT - identified as atleast three antenatal checkups done in SAT hospital.

Booked outside cases - Identified as atleast three antenatal checkups from peripheral hospitals other than SAT Hospital.

Unbooked cases - Identified as woman with no antenatal check ups.

2. Mode of delivery in previous pregnancies Whether vaginal delivery or had caesarean section.

3. Previous history of abruption

4. History of abortion - is identified as termination of pregnancy (spontaneous / induced) before 20 weeks of gestation.

5. History oflUD's and still births

6. Chronic hypertension - Defined as BP $>140 / 90 \mathrm{~m}$ of $\mathrm{Hg}$ recorded at 2 different occasions, 6 hrs apart, either before pregnancy or before 20 weeks of gestation.

7. $P I H$ - Defined as a blood pressure recording of $>140 / 90 \mathrm{~mm}$ of $\mathrm{Hg}$ at two different occasions, $6 \mathrm{hrs}$ apart, detected after 20 weeks of gestation and associated with proteinuria.

8. Eclampsia - Identified as seizures occurring in pregnant woman with history of PIH (No previous history of seizures). PROM Identified as rupture of membranes before onset of labour weeks of gestation and premature PROM identified as rupture of membranes after 20 weeks and before 37 weeks.

9. Overt diabetes - Diabetes diagnosed before pregnancy - it could be insulin dependent or on hypoglycemic agents.

10. GDM - Identified as two abnormal values in glucose tolerance test (values of normal glucose tolerance test - 95/180/155/140 $\mathrm{mg} / \mathrm{dl})$. 
11. Thrombotic episodes - History of DVT, stroke, pulmonary embolism.

12. Thrombotic episodes in parents, siblings, uncles and aunts (maternal as well as paternal

13. Addictions - Smoking (active / passive)Intake of alcohol Drug abuse

14. Trauma during present pregnancy - Direct abdominal trauma / intercourse.

15. Anaemia in pregnancy - Identified as haemogolbin less than $10 \mathrm{gm} / \mathrm{dl}$ during the antenatal period.

16. IUGR - Defined as abdominal circumference or estimated fetal weight less than the $10^{\text {th }}$ centile, detected by USG.

17. Hydramnios - Identified as amniotic fluid index more than $24 \mathrm{~cm}$ or largest vertical fluid pocket $>2 \mathrm{~cm}$.

18. Oligamnios - Identified as amniotic fluid index $<5 \mathrm{~cm}$.

19. Chorioamnionitis - Identified as axillary temperature of $38^{\circ} \mathrm{C} / 100.4^{\circ} \mathrm{F}$, after rupture of membranes with no other causes of fever.

20. Presentation of the fetus - Vertex, non vertex.

21. Sex of the fetus - male / female. Noted after delivery. Socio-economic status, demographic characteristics were also studied.
22. Socio-economic status - Scoring for socioeconomic status was based on Narayana Rao modification of Kuppuswami scale which is based on 3 major criteria like, monthly income, educational status and occupational status. A total score of $<10$ is low socioeconomic status.11-25 - Middle socioeconomic status 26-29 - High socio-economic status

\section{Statistical Methods}

The collected datas were entered in a master and the entry was done in Microsoft Excel sheet and analysis was done using SPSS package.

The measures used for the analysis of the data were chi-square test, students ' $t$ ' test $\&$ p value. $<0.05$ is considered as significant. Odds ratio and confidence interval was also calculated. Diagrams and charts were used to represent data where ever necessary to substantiate important findings.

\section{Observations and Results}

GE: $19.5 \%$ of women in the age group 30-34 years had abruption compared to $3.9 \%$ control (P value - 0.011) and hence the association is significant. There were no cases above 34 years in this study.

Table 1: Distribution of women according to age

\begin{tabular}{ll|c|c|c|c|}
\hline \multirow{2}{*}{ Age Group } & \multicolumn{2}{|c|}{ Case } & \multicolumn{2}{c|}{ Control } \\
\cline { 3 - 6 } & Frequency & Percentage & Frequency & Percentage \\
\hline$<25$ years & 40 & 51.9 & 47 & 61 \\
\hline 25-29 years & 22 & 28.6 & 27 & 35.1 \\
\hline 30 - 34years & 15 & 19.5 & 3 & 3.9 \\
\hline Total & $\mathbf{7 7}$ & $\mathbf{1 0 0}$ & $\mathbf{7 7}$ & $\mathbf{1 0 0}$ \\
\hline $\mathrm{X}^{2}=9.073$, & $\mathrm{P}$ value-0.011 \\
OR $=5.874$, & $95 \% \mathrm{Cl}(1.6-21.7)$
\end{tabular}

Table-2: Distribution of women according to socio-economic status

\begin{tabular}{|l|c|c|c|c|}
\hline \multirow{2}{*}{$\begin{array}{l}\text { Socio-economic } \\
\text { status }\end{array}$} & \multicolumn{2}{|c|}{ Case } & \multicolumn{2}{c|}{ Control } \\
\cline { 2 - 5 } & Frequency & Percentage & Frequency & Percentage \\
\hline Low & 50 & 64.9 & 34 & 44.2 \\
\hline Middle & 14 & 18.2 & 33 & 42.9 \\
\hline High & 13 & 16.9 & 10 & 13 \\
\hline Total & $\mathbf{7 7}$ & $\mathbf{1 0 0}$ & $\mathbf{7 7}$ & $\mathbf{1 0 0}$ \\
\hline $\mathrm{X}^{2}=11.1$, & $\mathrm{P}$ value -0.004 & & \\
OR $=0.288$, & $95 \% \mathrm{Cl}(0.135-0.618)$
\end{tabular}




\section{JMSCR Vol||09||Issue||03||Page 122-129||March}

From the above table, it is clear that $64.9 \%$ of women with monthly income <Rs. 1000 had abruption compared to $44.2 \%$ control. This association is statistically significant.

Table-3: Distribution of women according to the booking status

\begin{tabular}{|l|c|c|c|c|}
\hline \multirow{2}{*}{ Booking Status } & \multicolumn{2}{|c|}{ Case } & \multicolumn{2}{c|}{ Control } \\
\cline { 2 - 5 } & Frequency & Percentage & Frequency & Percentage \\
\hline Booked in SATH & 28 & 36.4 & 64 & 83.1 \\
\hline Booked outside & 49 & 63.6 & 13 & 16.9 \\
\hline Total & $\mathbf{7 7}$ & $\mathbf{1 0 0}$ & $\mathbf{7 7}$ & $\mathbf{1 0 0}$ \\
\hline
\end{tabular}

$\mathrm{X}^{2}=32.5, \quad$ P value -0.000

$\mathrm{OR}=5.9, \quad 95 \% \mathrm{Cl}(1.4-23.8)$

This table shows that $63.6 \%$ of the women with antenatal checkups from hospitals other than SATH had abruption compared to $16.9 \%$ of the women who had antenatal checkups in SATH. Statistically it was found to be significant. This is because of more cases being referred to a referral centre like ours. There were no unbooked cases in this study. This table measures the risk of parity on abruption. $15.6 \%$ of the women with two previous deliveries had abruption compared to $4 \%$ control. It is significant. In this study there were no women with partiy more than 2 .

Table-4: Distribution of women according to parity

\begin{tabular}{|l|c|c|c|c|}
\hline \multirow{2}{*}{ Parity } & \multicolumn{2}{|c|}{ Case } & \multicolumn{2}{c|}{ Control } \\
\cline { 2 - 5 } & Frequency & Percentage & Frequency & Percentage \\
\hline Primi & 37 & 48 & 44 & 57.1 \\
\hline Para-1 & 28 & 36.3 & 30 & 38.9 \\
\hline Para-2 & 12 & 15.6 & 3 & 4 \\
\hline Total & $\mathbf{7 7}$ & $\mathbf{1 0 0}$ & $\mathbf{7 7}$ & $\mathbf{1 0 0}$ \\
$\mathrm{X}^{2}=16.2$, & $\mathrm{P}$ value-0.046 \\
OR $=4.6$, & $95 \% \mathrm{Cl}(1.2-18.1)$
\end{tabular}

Table-5: Distribution of women according to the mode of delivery in previous pregnancy

\begin{tabular}{|l|c|c|c|c|}
\hline \multirow{2}{*}{$\begin{array}{c}\text { Mode } \\
\text { delivery }\end{array}$} & \multicolumn{2}{|c|}{ Case } & \multicolumn{2}{c|}{ Control } \\
\cline { 2 - 5 } & Frequency & Percentage & Frequency & Percentage \\
\hline Vaginal & 24 & 66.7 & 29 & 93.5 \\
\hline Caesarean & 12 & 33.3 & 2 & 6.5 \\
\hline Total & $\mathbf{3 6}$ & $\mathbf{1 0 0}$ & $\mathbf{3 1}$ & $\mathbf{1 0 0}$ \\
\hline
\end{tabular}

$\begin{array}{ll}\mathrm{X}^{2}=7.3, & \mathrm{P} \text { value }-0.007 \\ \mathrm{OR}=7.2, & 95 \% \mathrm{Cl}(1.5-35.6)\end{array}$

This table shows that, in this study, women with the history of caesarean delivery in the previous pregnancy had an increased incidence of abruption in the present pregnancy. $33.3 \%$ women with the history of caesarean section had abruption compared to $6.5 \%$ of control.

It can be interpreted from the above given table that PIH is a risk factor for abruption, in 
Table-6 : Distribution of women according to PIH

\begin{tabular}{l|l|c|c|c|c|}
\hline \multirow{2}{*}{ PIH } & \multicolumn{2}{|c|}{ Case } & \multicolumn{2}{c|}{ Control } \\
\cline { 2 - 5 } & Frequency & Percentage & Frequency & Percentage \\
\hline Absent & 56 & 72.7 & 70 & 90.9 \\
\hline Present & 21 & 27.3 & 7 & 9 \\
\hline Total & $\mathbf{7 7}$ & $\mathbf{1 0 0}$ & $\mathbf{7 7}$ & $\mathbf{1 0 0}$ \\
\hline $\mathrm{X}^{2}=7.4$, & P value -0.006 & \\
$\mathrm{OR}=3.7$, & $95 \% \mathrm{Cl}(1.5-9.3)$
\end{tabular}

In this study. $27.3 \%$ of women had abruption with PIH compared to $9 \%$ of control with PIH

Table-7: Distribution of women according to sex. of the fetus

\begin{tabular}{l|l|c|c|c|c|}
\hline \multirow{2}{*}{ Sex of the fetus } & \multicolumn{2}{|c|}{ Case } & \multicolumn{2}{c|}{ Control } \\
\cline { 2 - 5 } & Frequency & Percentage & Frequency & Percentage \\
\hline Male & 35 & 45.5 & 46 & 59.7 \\
\hline Female & 42 & 54.5 & 31 & 40.3 \\
\hline Total & $\mathbf{7 7}$ & $\mathbf{1 0 0}$ & $\mathbf{7 7}$ & $\mathbf{1 0 0}$ \\
\hline $\mathrm{X}^{2}=3.2, \quad \mathrm{P}$ value -0.074 \\
$\mathrm{OR}=1.8, \quad 95 \% \mathrm{Cl}(0.9-3.4)$
\end{tabular}

It is evident from this table that $54.5 \%$ of the women who had abruption carried a female fetus compared to $40.3 \%$ control ( $\mathrm{P}$ value 0.074 ) and it was found to be statistically significant. It may be an incidental finding.

\section{Discussion}

The etiology of abruption is not known but there are several associated conditions. Although the cause is sometimes obvious, as in case of direct trauma to the uterus, such cases are uncommon and in most cases the causes unknown. The aim of this study is to assess the risk factors associated with abruption.

Age

In this study, increasing age has been found to be associated with abruptio placentae. $19.5 \%$ of cases between 30-34- yrs of age had abruption compared to $3.9 \%$ of control group. There were no cases above 34 years in the study.

Kramer et $\mathrm{al}^{1}$ (1997) reported that abruption is more common with increasing age. Rasmussen et al $(1996)^{4}$ found that the risk increased with age. Sheiner et al $^{2}$ (2003) found advanced age to be independently associated with the occurrence of placental abruption. Toivonen $\mathrm{S}$ and associates ${ }^{3}$ (2002) reported advanced maternal age (>35 yrs) was an independent risk factor of abruption.

\section{Parity}

Increasing parity was found to be a risk factor for abruption ( $\mathrm{P}$ value of $(0.000)$ and odds ratio of 4.7). $15.6 \%$ of cases of abruption had parity 2 and $4 \%$ of the woman in the control group were para-

2. There were no women in this study with party more than two. Kramer et al ${ }^{1}$ (1997) reported that abruption is more common with high parity Rasmussen et $\mathrm{al}^{4}$ (1966) found that birth order 2 had lowest proportion Pritchard and colleagues ${ }^{5}$ (1991) have also shown it to be higher in women of greater parity. Ananth $\mathrm{CV}$ and associates ${ }^{6}$ (1996) found an increased risk of abruption with higher parity among younger women only. In addition, an analysis of the joint effects of age and parity on placental abruption indicated a strong parity effects for women under 30 years of age. Prochazka M and associates ${ }^{7}$ (2005) confirmed that higher parity is a risk factor for abruption.Abu Heija and colleagues ${ }^{8}$ (1998) showed that abruption occurred more in parous women.

\section{Socio-economic status}

In this study, incidence of abruption was found to be statistically significant in women with low socio-economic status. $64.9 \%$ of cases were in 
low socio-economic group compared to $44.2 \%$ in control. Dietary deficiency may be attributed for this finding. Naeye et $\mathrm{al}^{9}$ (1979) found placental abruption to be the most common cause of fetal loss in an African city and was strongly associated with maternal poverty and malnutrition.

\section{Booking status}

In this study, 49 women (63.6\%) with abruption had antenatal checkups from hospitals other than SATH TVM compare to $16.9 \%$ of women who were booked in SATH, TVM. A statistically significant difference was found between cases booked in hospitals other than SATH, TVM and cases booked in SATH. This may be due to increased number of cases of abruption being referred to a tertiary center like SATH.

\section{Mode of delivery in previous pregnancy}

$33.3 \%$ cases with abruption placenta had previous history of caesarean section compared to $6.5 \%$ of control. In this study previous caesarean was associated with abruption. Lydon-Rochelle $\mathrm{M}$ and associates $^{10}$ in 2001 reported significantly increased risk of abruption placentae in women and first caesarean birth. Rasmussens, Igrens LM, Dalakerk $^{11}$ (1999) reported caesarean section in the previous delivery as an increased the risk of placental abruption by $40 \%$.

\section{Pregnancy induced hypertension}

Pregnancy induced hypertension was associated with increased incidence of abruption in this study. A total of 21 cases $(27.3 \%)$ had PIH compared to $9 \%$ in control group. Morgan and colleagues $^{12}$ in 1994 found that hypertensive women were more likely to suffer from a more severe abruption. Ananth et $\mathrm{al}^{13}$ (1997) found strong association between severe preeclampsia and superimposed preeclampsia on within hypertension and risk of abruptio placenta. Ananth and associates $^{14}$ (1999b) reported a fourfold increased incidence of abruption with severe preeclampsia. Sheiner E and et $\mathrm{al}^{2}$ (2003) reported that abruption of the placenta was found to be significantly associated with $\mathrm{PIH}$.

Dafallah SE, Babikir $\mathrm{HE}^{15}$ (2004) found an increased risk of abruption in patients with hypertension and preeclampsia.

Prochazka M and associates ${ }^{7} 2005$ found preeclampsia is statistically significant risk factor for abruption.

There were no cases of chronic hypertension in this study.

\section{Sex of the fetus}

In our study $54.5 \%$ women with female foetus had abruption compared to $40.8 \%$ of control which was found to be a significant risk factor for abruption. This may be an incidental finding. But Kramer et al $^{1}$ (1997) concluded that male fetal sex is a significant etiologic determinant of placental abruption but in our study such association was not found.

\section{Summary and Conclusion}

- This was a case control study.

- The aim is to study the risk factors associated abruption placenta.

The total of 154 women were recruited for the study during a period of 12 months. There were 77 cases an equalnumber of controls.

\section{Conclusion}

The following risk factors are associated with abruption placentae.

Age: Advanced aged (30-35 yrs) was found to be associated with increase chance of abruptio placentae.

Multiparty: (Women with parity 2) is a risk factor for abruptio placentae.

Low socio-economic status : Increased incidence of abruptio placentae was associated with low socio-economic status.

Booking status: Number of cases of abruption were more in women who had antenatal checkups from hospitals other than SATH. This significance may be due to increased cases of abruption being referred to tertiary center like ours.

Pregnancy induced hypertension: PIH was associated with increased incidence of abruptio placentae. 
Female sex Women with female fetuses had showedincreasedEpidemiol, 144(9): 881-9.tudy. It may be an incident

\section{References}

1. Kramer MS, Usher RH, Pollack R, Boyd M, Usher S (1997) : Etiologic determinants of abruptio placentae. Obstet Gynecol, 89:221226

2. Sheiner E, Shoham-Vardi I, Hallak M, Hadar A, Gortzak- Uzan L, Katz M, Mazor M (2003) : Placental abruption in term pregnancies: clinical significance and obstetric risk factors. J Matern Fetal Neonatal Med., 13(1):45-9

3. Toivonen S, Heinonen S, Anttila M, Kosma VM, Saarikoski S (2002) : Reproductive risk factors, Doppler findings, and outcome of affected births in placental abruption: a population-based analysis. Am J Perinatol, 19(8):451-60.

4. Rasmussens, Irgens LM, Bergsjo P, Dalaker K (1996a) : The occurrence of placental abruption in Norway 1967-91. Acta Obstet Gynecol Scand 75:222-228.

5. Pritchard JA, Cunningham FG, Pritchard SA, Mason RA (1991): On reducing the frequency of severe abruptio placentae. Am J Obstet Gynecol 165:1345

6. Ananth CV, Savitz DA, Luther ER (1996) : Maternal cigarette smoking as risk factor for placental abruption, placenta previa, and uterine bleeding in pregnancy. Am J Epidemiol, 144(9): 881-9.

7. Prochazka M, Kudela M, Lubusky M, Vetr M, Hrachovec P, Zielina P (2005) : Premature separation of the placentae - etiology and risk factors. Ceska Gynecol, 70(3): 175-9.

8. Ananth CV, Savitz DA, Luther ER (1996) : Maternal cigarette smoking as risk factor for placental abruption, placenta previa, and uterine bleeding in pregnancy. Am J
9. Naeye RL, Tafari N, Marbac CC (1979) : Perinatal death due to abruptio placentae in an African city. Acta Obstet Gynecol Scand 58:37-40.

10. Lydon-Rochelle M, Holt VL, Easterling TR, Martin DP (2001)First-birth cesarean and placental abruption or previa at second birth. Obstet Gynecol, p. 765-9.

11. Rasmussen S, Irgens LM, Dalaker K. A history of placental dysfunction and risk of placental abruption. Paediatr Perinat Epidemiol. 1999 Jan; 13(1):9-21.

12. Morgan MA, Berkowitz KM, Thomas SJ, Reimbold P, Quilligan EJ (1994) : Abruptio placentae: Perinatal outcome in normotensive and hypertensive patients, 170:1595-1599.

13. Ananth CV, Savitz DA, Bowes WA Jr., Luther ER (1997) : Influence of hypertensive disorders and cigarette smoking on placental abruption and uterine bleeding during pregnancy. BJOG (1997) 104:572-578.

14. Ananth CV, Smulian JC, Vintzileos AM (1999) : Incidence of placental abruption in relation to cigarette smoking and hypertensive disorders during pregnancy: a meta-analysis of observational studies. Obstet Gynecol, 93(4):622-8.

15. Dafallah SE, Babikir HE (2004) : Risk factors predisposing to abruptio placentae. Maternal and fetal outcome. Saudi MedJ., 25(9): 123740. 